\title{
November 2018
}

True (A) or false (B):

Medicolegal responsibilities for the administration of intravenous contrast media by radiographers: Radiologists' perspectives

1. Informed consent allows a patient to make decisions regarding their own treatment and further management.

2. Currently radiographers in SA are formally trained to manage and treat patients and to prescribe drugs.

Legalising physician-assisted suicide in South Africa: Should it even be considered?

3. South African law discriminates between euthanasia and physicianassisted suicide.

4. The South African Constitution holds individualism on the same level as communitarianism.

5. The Living Will may not serve as a proxy in determining crucial further medical management of patients.

Mandatory HIV testing as a prerequisite for surgical procedures: Perspectives on rights and ethics

6. The Universal Declaration of Human Rights was adopted to guarantee and safeguard the inherent dignity and equality of every being.

7. Patients do not have the right to refuse treatment.

Do Tanzanian hospitals need healthcare ethics committees? Report on the 2014 Dartmouth/Penn Research Ethics Training and Program Development for Tanzania (DPRET) workshop

8. The culture and policies of hospitals, group practices, insurers and other health system organisations shape individual clinician-patient relationships.

9. Bioethics is not a relatively new concept in sub-Saharan Africa.

Involuntary sterilisation of HIV-positive women in South Africa: A current legal perspective

10. Involuntary sterilisation of women who are HIV-positive is allowed within the framework of South African law.
11. The social, cultural and gendered pressure on women to bear children has a bearing on their self-worth and dignity.

12. Section 12 of the South African Constitution provides rights regarding the freedom and security of the person.

13. The Sterilisation Act deals only with instances where consent cannot be obtained for sterilisation.

Unpacking the 2-year age-gap provision in relation to the decriminalisation of underage consensual sex in South Africa

14. The age of consent to sex has recently been changed to 12 years in South African law.

\section{CRISPR: Challenges to South African biotechnology law}

15. The Genetically Modified Organisms Act No. 15 of 1997 does not require information on socioeconomic considerations when applying to pursue GMOs.

16. Genome editing does not require the incorporation of foreign DNA.

Partial-birth abortion - is it legally and ethically justifiable? Lessons for South Africa

17. Partial-birth abortion is likened to infanticide by some pro-life advocates.

18. South Africa's Choice on Termination of Pregnancy Act is not universally hailed as one of the world's most liberal pieces of legislation.

19. Medical evidence suggests that the structures required to experience pain begin to manifest during the first trimester.

WhatsApp in a clinical setting: The good, the bad and the ugly

20. Section 14 of the Bill of Rights of the South African Constitution entrenches a patient's right to privacy.

A maximum of 3 CEUs will be awarded per correctly completed test.

The CPD programme for SAJBL is administered by Medical Practice Consulting.

CPD questionnaires must be completed online at www.mpconsulting.co.za

After submission you can check the answers and print your certificate.

Questions may be answered up to 6 months after publication of each issue.

Accreditation number: MDB015/030/01/2018 (Ethics) 